\title{
Impacts of Famers' Participation in Upscaling Technologies on Mungbean (Vigna radiata L.) Production in the South-Western Region of Bangladesh
}

\author{
M. A. Islam ${ }^{1}$, M. R. Islam², M. E. Haque ${ }^{1}$, F. Yeasmin ${ }^{1 *}$ and M. A. Hossain ${ }^{1}$ \\ ${ }^{1}$ Department of Agricultural Extension and Rural Development; ${ }^{2}$ Department of Agronomy, \\ Bangabandhu Sheikh Mujibur Rahman Agricultural University, Gazipur-1706, Bangladesh \\ *Corresponding author and Email: farhanaer@bsmrau.edu.bd
}

Received: 24 April 2014

Accepted: 13 December 2014

\begin{abstract}
The study evaluated the farmers' participatory methods of upscaling technologies for increasing mungbean production in the south-western region of Bangladesh. It was a descriptive survey study and data were collected by interviewing 120 sample farmers in DFID-Mungbean Project areas in Bangladesh. The participatory methods trailed in the project were farmers seed exchange program, demonstrations trials, agricultural training and workshops on mungbean production. However, farmers to farmers seed exchange program was identified as the most effective method. During the project phase, the farmers selected and adopted their preferred mungbean varieties, developed and practiced appropriate land preparation techniques along with improved post-harvest operations. Farmers' participation in technology generation and upscaling resulted in increasing area and production of the mungbean many fold during 2004 to 2008 . The average yield of mungbean was $1370 \mathrm{~kg} / \mathrm{ha}$ and almost all framers obtained yields more than that of the national average of $705 \mathrm{~kg} / \mathrm{ha}$. Agricultural training, farm size and extension contact accounted for $83 \%$ of the total variation in upscaling technology and $90 \%$ of the variation in yield of mungbean. The extent of upscaling technology in terms of increase in area and yield of mungbean were associated with various participatory methods practiced by the farmers in the study area.
\end{abstract}

Keywords: Farmers' participation, upscaling technology, mungbean production

\section{Introduction}

Mungbean (Vigna radiata $\mathrm{L}$.) is one of the most important pulse crops in Bangladesh. The variation of the growth rates in mungbean production was $-21.55 \%$ to $20.26 \%$ during the period 1968-2011 and thereby, the projection of production indicated the vital potential of mungbean in Bangladesh (Rahman et al., 2013). This is presumably due to the development of disease resistant, bold-seeded, high yielding and early maturing varieties and associated improved production technologies. In Bangladesh, nearly
$65 \%$ of the total mungbean area is concentrated in the southern districts (Afzal et al., 2004). Mungbean was introduced in the south-western district of Jessore, Jhenaidah, Chuadanga, Meherpur, and Kustia through DFID-Mungbean Project in collaboration with Lentil, Blackgram, and Mungbean Development Pilot (LBMDP) Project under the Ministry of Agriculture for its immense potentiality to expand in these areas. Because of late harvest of Aman rice in the area, a significant portion of land remains suitable for mungbean cultivation. Therefore, the project launched a systematic production program 
integrating the research and development activities. The program brought together the participating and enthusiastic farmers through creating awareness of using available technologies to boost up mungbean production. Thus, mungbean cultivation has been expanded through some quantitative, qualitative and cultural changes due to various interventions in the project areas.

The LBMDP project followed the farmers' participatory approach in the processes of technology generation and upscaling to minimize gap between the potential yield and the farmers yield towards self-sufficiency in mungbean production and to reduce import. The whole program was implemented with the involvement of different stakeholders in each step of planning, execution and evaluation. Various participatory methods involving planning workshop, training, field demonstration, farmers' rally or field day, seed production and exchanges were followed in the project area. These activities gave an opportunity to enhance knowledge of the participating farmers on mungbean cultivation and even the neighbouring farmers who were not directly involved in the program. All the above steps along with the seed exchange by the participating farmers to noparticipating ones created good awareness about the new and improved varieties and production technologies of mungbean.

A participatory approach involving researchers, farmers and different stakeholders have been applied for testing new varieties and practices in mungbean by Robertson et al. (1998). The participatory approaches to agrarian development with a view to identifying the potential for and limitations to upscaling such approaches have been found to be successful in many countries of the world (Almekinders and Richards, 2007). Therefore, it appeared to be necessary to understand the extent of participation, improvement of knowledge on mungbean cultivation and its consequences on mungbean production in the areas. The outcome of this study could be a model in attempting any new development program to explore mungbean cultivation towards increasing production of mungbean or other pulses to a substantial degree in other potential areas. In view of the above, this study was set forth aiming at evaluating the farmers using participatory methods, upscaling technologies and expansion of mungbean cultivation and finding out the relationships of participatory methods of the farmers with their technology adoption and increasing area and yield of mungbean in the south-western region of Bangladesh.

\section{Materials and Methods}

The study was a descriptive survey research and was designed to describe the farmers using participatory methods, and technology adoption and upscaling of mungbean cultivation. Eight villages under DFID-mungbean project area of Jessore and Jhenaidah districts were the locale of the study. Farmers who received training and production supports from DFID-mungbean project constituted the population of the study. The respondents were selected by two stages proportionate random sampling technique. Fifteen farmers were selected from each village by using disproportionate stratified random sampling to make the 120 sample farmers and to have homogenous representation.

In order to collect relevant information from the respondents, an interview schedule was prepared, pre-tested and used. The interview schedule contained both open and closed questions. Data were collected by interviewing the sample farmers in June 2008 by the researchers. Upscaling of mungbean production was considered as the dependent variable in this study. To measure the upscaling, a measuring scale containing seven items for farmers' participation in upscaling technologies of mungbean production was used. Each respondent was asked to answer all the items by giving a particular number depending on his answer.

The area and yield of mungbean as well as seeds of mungbean saved and distributed to other 
farmers were recorded through interview schedule. For describing the various independent and dependent variables, the respondents were classified into several categories in respect of each variable. One item scale was used to measure the use of participatory methods by the farmers for mungbean cultivation. Each of the methods was assigned a score (number/year) by the respondents. To determine the use of participatory methods, the total score obtained by a respondent was calculated by summing up the scores against each of the methods and then divided by total number of respondents to obtain mean using of participatory methods.

We selected eight socio-demographic characteristics of the farmers as independent variables of the study. The selected independent variables included: age, education, wealth status, family size, farm size, agricultural training received, extension contact, and problem confrontation were measured either by putting numerical scores or through scales. For describing the various independent and dependent variables, the respondents were classified into several categories in respect of each variable.

In determining technology adoption, the total score obtained by a respondent was calculated by summing up the scores against each of the technologies. The technology adoption by the farmers for mungbean cultivation during preproject and post-project period was measured by total weighted score for each technology. The statistical measures such as frequency counts, percentages, range, mean, and standard deviation were used to describe the data. For exploring the relationship among participatory methods of the farmers and their technology adoption in increasing area and yield of mungbean, coefficient of correlation (r) was used for rejecting or accepting null hypothesis. Multiple regression analysis was used to determine the contribution of independent variables on the dependent variable.

\section{Results and Discussion}

\subsection{Participatory methods in upscaling technologies}

Among various participatory methods, participation of farmers in seed exchange program was ranked in the first position (Table 1). Seeds of mungbean produced in the farmers' plots were distributed through farmer to farmer seed exchange program (Afzal et al., 2004). Nearly 16,605 tons of mungbean seeds were distributed at the beginning of the year 2000 to facilitate mungbean production in the regions. It was observed that farmer to farmer seed exchanges were near-saturation condition at the time of study.

Table 1. Participatory methods of upscaling technologies in mungbean production

\begin{tabular}{llcc}
\hline Participatory methods & $\begin{array}{c}\text { Mean* } \\
\text { score }\end{array}$ & $\begin{array}{c}\text { Standard } \\
\text { deviation }\end{array}$ & $\begin{array}{c}\text { Rank } \\
\text { order** }\end{array}$ \\
\hline i. $\quad$ Participation in farmers to farmers seed exchange & 1.92 & 0.78 & I \\
$\quad$ program & 1.82 & 0.70 & II \\
ii. $\quad$ Participation in demonstration trial & 1.04 & 1.15 & III \\
iii. $\quad$ Participation in training session in the office of & & \\
$\quad$ Upazila Agricultural Officer of DAE & 0.85 & 0.35 & IV \\
iv. $\quad$ Orientation training on mungbean cultivation & 0.11 & 0.34 & V \\
v. Participation in regional workshop of the project & 0.09 & 0.29 & VI \\
vi. $\quad$ Participation in planning workshop of the project & 0.06 & 0.24 & VII \\
vii. Participation in mobile workshop with high official & & \\
$\quad$ for monitoring and evaluation & & \\
* Total weighted score (number/year) of each item divided by total respondents. &
\end{tabular}


Next to this, demonstration trials greatly helped to popularize the new HYV mungbean in the region. For this, a total 11,280 demonstration trials were set in 47 upazilas of 15 districts through the Department of Agriculture Extension (DAE) under the LBMDP Project (Afzal et al., 2004). Participation in various training programs was also another important participatory method of technology upscaling. In the training session, farmers were given attractive posters and leaflets describing the variety with explanation of the improved production technologies. Besides these, the farmers attended the orientation training, regional workshop, and planning workshop of the project for technology upscaling and increase mungbean production.

Figure 1 reveals that $14 \%$ of the respondents belonged to low level participation, while others belonged to the groups of moderate to good level of participation. This indicates that all participatory methods coupled with the seed exchange program from the participating farmers created a good level of awareness about the new and improved varieties and technologies of mungbean compared to non participating ones. The finding also conforms with that of Afzal et al. (2004).

\subsection{Upscaling of improved production technologies}

Improved variety, appropriate land preparation, post-harvest operation, timely harvesting, and timely seed sowing, fertilization, plant protection, and irrigation were the improved technologies of mungbean production (Table 2). During pre-project period none of the respondents were conversant with the improved variety, appropriate land preparation techniques and improved post-harvest operations.

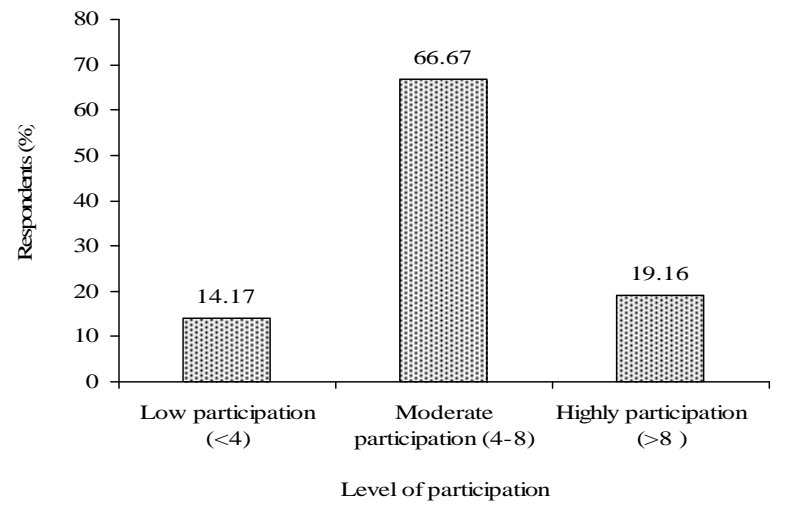

Figure 1. Distribution of farmers oriented towards participatory methods in technology up scaling

Table 2. Technology adoption by the farmers during pre-project and post-project period

\begin{tabular}{llcc}
\hline \multirow{2}{*}{ Technology } & \multicolumn{2}{c}{ Distribution of respondents (\%) } \\
\cline { 3 - 4 } & & Pre-project period & Post-project period \\
\hline i. & HYV variety of mungbean & 00 & 100 \\
ii. & Appropriate land preparation & 00 & 100 \\
iii. & Improved post-harvest operations & 00 & 100 \\
iv. & Timely harvesting & 10 & 90 \\
v. & Plant protection & 17 & 83 \\
vi. & Fertilization & 26 & 74 \\
vii. & Timely seed sowing & 30 & 70 \\
viii. & Irrigation & 40 & 60 \\
\hline
\end{tabular}


During pre-project period none of the respondents were conversant with the improved variety, appropriate land preparation techniques and improved post-harvest operations. However, some of the respondents were familiar with appropriate time of sowing and harvesting, and other management like irrigation, fertilization and plant protection. During post-project phase, all the respondents adopted improved varieties, practicing appropriate land preparation techniques, and following improved post-harvest operations. The uses of other production technologies increased substantially.

During post-project period, farmers who were involved in the demonstration trials were generally invited to participate in a training session followed by the distribution of packages of seeds and other inputs. The seeds produced by the farmers were collected and distributed to the neighboring farmers through direct supervision of the project personnel. Demonstrations were set in well-communicated fields to expose those technologies to other farmers. All of the stated steps coupled with farmers to farmers seed exchange program created a synergistic effect on awareness building among the pulse growers to use new and improved technologies. On the basis of computed score, the respondents were filed into three groups (Fig. 2). The majority of the respondents had moderate level of technology adoption. The findings are in conformity with those observed by Islam (2002). This also suggests that almost all the respondents adopted available mungbean cultivation technologies. The short-growth duration and MYMV-resistant and high yield were the main reasons for easy adoption of mungbean cultivation (Grover et al., 2004).

\subsection{Enhancing mungbean production}

The frequency distribution of yield performance showed nearly a normal distribution with slightly skewed $(\alpha=0.94)$ towards right (Fig. 3). This indicated that most of the farmers obtained seed yield less than average $(1370 \mathrm{~kg} / \mathrm{ha})$, although about $40 \%$ farmers obtained much higher yield compared to this average and almost all framers obtained yields more than the national average of $705 \mathrm{~kg} / \mathrm{ha}$. The higher yield may be attributed to the improved knowledge of the farmers on mungbean production system along with easy adaptation of new varieties. The other attributes were the use of recommended rates of seed and fertilizer, and use of pesticides. It was reported that yield of mungbean in the summer varied from 250 to $1875 \mathrm{~kg} / \mathrm{ha}$ and most of the farmers obtained yields of 500 to $1200 \mathrm{~kg} / \mathrm{ha}$ (Grover et al., 2004).

Low technology adoption $(<12)$

$\square$ Moderately technology adoption (12-13)

国 Highly technology adoption (>13)

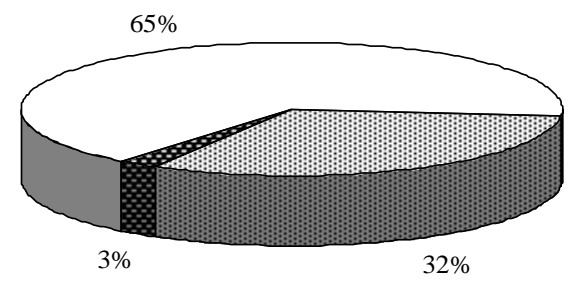

Figure 2. Distribution of farmers according to the extent of technology upscaling 


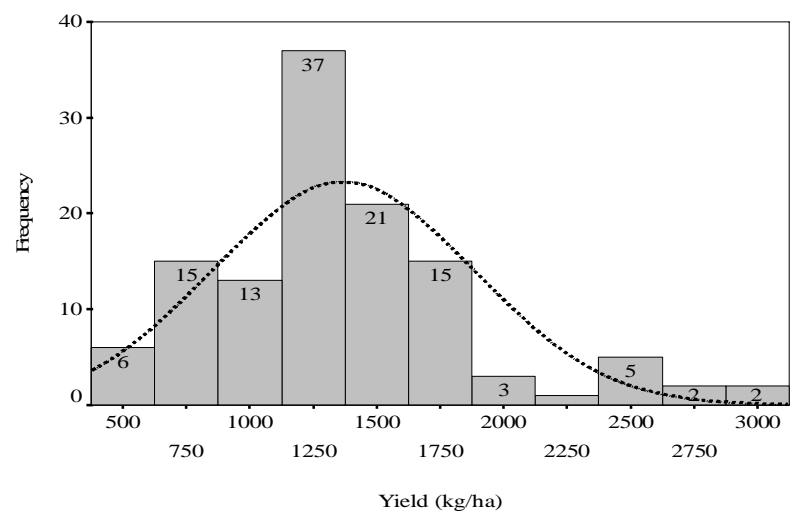

Figure 3. Frequency distribution of the farmers according to yield performance of their preferred varieties of mungbean

The area and production of mungbean were in increasing trends during 2004-2008 (Figure 4). The area and yield of most pulses in Bangladesh are either declined or stagnated but mungbean registered an increasing trend (Afzal et al., 2004). Sankhayan and Sood (1984) observed that mungbean also showed some increase in production at $2.8 \%$ per annum during $1960-61$ to 1980-81. However, the increasing rates over the years compared to previous year were in decreasing trend indicating that in near future, these increasing rates may reach plateau. The increasing area and yield of mungbean were attributed to the uses of short-duration, diseaseresistant and high-yielding varieties, and application of insecticides, timely sowing, at least two weeding along with congenial climatic conditions.

\subsection{Farmer to farmers seed exchange program}

Farmers to farmers seed exchange program was successful where $77 \%$ of the farmers saved seed for the next year and a significant number of them $(66 \%)$ distributed seeds to other farmers as per request (Table 3 ). The seeds saved by the farmers ranged from 1 and $30 \mathrm{~kg}$ in 2007 with an average of $11 \mathrm{~kg}$. Most of the farmers saved 5 to $10 \mathrm{~kg}$ of seeds for sowing. At least three farmers used to request seed from the neighboring farmers for sowing in the next year. Farmers distributed about $7.8 \mathrm{~kg}$ seeds to other farmers with a range between 1 and $25 \mathrm{~kg}$. The farmers generally used earthen pot, gunny bag, tin, gunny bag with polythene for storing seeds. These methods of storing have also been advocated as standard but with the addition of naphthalene or camphor at the rate of $5 \mathrm{~g} / \mathrm{kg}$ seed (Kabir, 2007).

\subsection{Technology upscaling and mungbean production}

Regression analysis was performed to look into how the changes in dependent variables were influenced by the changes in independent variables. From the analysis, it was revealed that farm size, agricultural training, and extension contact had significant influence on the yield of mungbean (Table 4). These three independent variables altogether contributed to $83 \%$ of the total variations in up scaling technology and $90 \%$ of the variations in yield of mungbean. Among these, agricultural training had the highest contribution to yield of mungbean. Training also had significant contribution to up scaling of technology, whereas extension contact and farm size had no such contribution, although these two variables contributed greatly to increase yield of mungbean. Chowdhury (1997) indicated that farm size also had a strongly positive relationship with up scaling of technologies. Okoro and Obibuaka (1992) and Sarkar (1997) also reported similar results. 


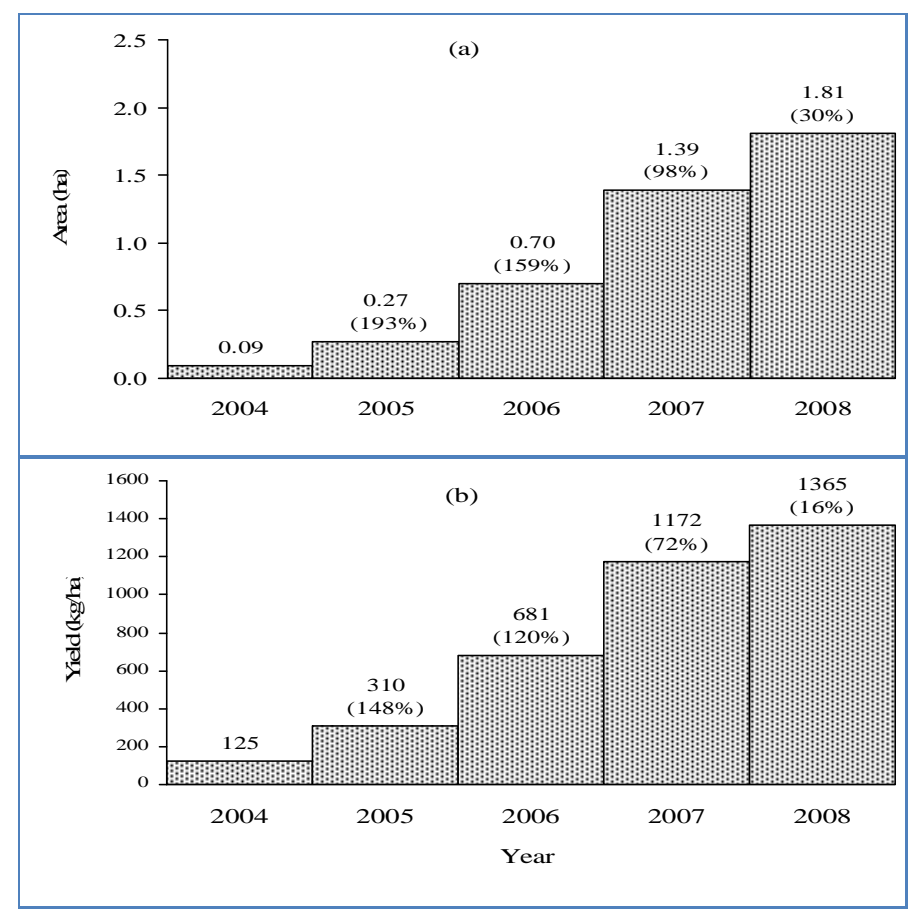

Figure 4. Scenario of area (a) and yield (b) of mungbean for the last five years (2004- 2008) Values in the parenthesis indicate percent decrease over the previous year

Table 3. Seed saving and distribution to other farmers

\begin{tabular}{llcccc}
\hline \multicolumn{1}{c}{ Items } & $\begin{array}{c}\text { Farmers } \\
(\%)\end{array}$ & $\begin{array}{c}\text { Range } \\
(\mathrm{kg})\end{array}$ & Mean & $\begin{array}{c}\text { Standard } \\
\text { deviation }\end{array}$ \\
\hline i. & Saved seeds for next year & 77 & $1-30$ & 11 & 7.4 \\
ii. & $\begin{array}{l}\text { Distributed seeds to others } \\
\text { iii. }\end{array}$ & 66 & $1-25$ & 7.8 & 5.75 \\
& $\begin{array}{l}\text { Number of farmers asking for the } \\
\text { seeds from the growers by the non- } \\
\text { growers }\end{array}$ & - & $1-10$ & 3.20 & 1.96 \\
\hline
\end{tabular}

Table 4. Characteristics showing the contribution to farmers' technology upscaling and yield of mungbean

\begin{tabular}{llcc}
\hline \multicolumn{2}{l}{ Variables } & \multicolumn{2}{c}{ Regression coefficient $\left(\mathrm{R}^{2}\right)$} \\
\cline { 3 - 4 } & & Technology upscaling & Yield of preferred variety \\
\hline i. & Farm size & - & $20.52^{* *}$ \\
ii. & Agricultural training & $0.21^{* *}$ & $55.85^{* *}$ \\
iii. & Extension contact & - & $44.28^{* *}$ \\
iv. & Co-efficient of determination & 0.83 & 0.90 \\
v. & Constant & $11.12^{* *}$ & $197.97 * *$ \\
\hline
\end{tabular}

Note: ** indicates significance at 0.01 level 
Table 5. Relationships among participatory methods, technology upscaling and increasing area and yield of mungbean

\begin{tabular}{lccc}
\hline Characteristic & \multicolumn{2}{c}{ Correlation coefficient (r) } \\
\cline { 2 - 4 } & $\begin{array}{c}\text { Technology } \\
\text { upscaling }\end{array}$ & $\begin{array}{c}\text { Area (ha) increasing } \\
\text { over time }\end{array}$ & $\begin{array}{c}\text { Yield (kg/ha) increasing } \\
\text { over time }\end{array}$ \\
\hline $\begin{array}{l}\text { Use of participatory } \\
\text { methods }\end{array}$ & $0.20^{*}$ & $0.24^{* *}$ & $0.21^{*}$ \\
\hline
\end{tabular}

Note: $*$ and $* *$ indicate significance at 0.05 and 0.01 level, respectively.

\subsection{Relationships between participatory methods and mungbean production}

Farmers using participatory methods had positive effect on technology upscaling (Table 5). This result had conformity with that of Shanker (1996) who found significant relationship of organizational participation with the level of knowledge in vegetable production technology. The participatory methods also had positive significant relationships with the increase in area of mungbean cultivation. The positive relationship between participatory methods and increasing production of mungbean over time indicted that higher the use of participatory methods, higher the production of mungbean.

\section{Conclusions}

Majority of the respondents adopted various participatory methods in cultivating mungbean. The upscaling of various technologies like improved variety, appropriate land preparation and improved post-harvest operations had $89 \%$ yield advantage over national average in the study area. The savings of seeds for farmers' own use, and asking for seeds from the growers by the non-growers were strongly evident. Farm size, extension contact, agricultural training had positive significant relationship with the upscaling of technologies and yield of mungbean. Adoption of various participatory methods had the biggest impact on increasing yield and expansion of mungbean cultivation in the study area.

\section{References}

Afzal, M. A., Bakr, M. A., Hamid, A., Haque, M. M. and. Aktar, M. S. 2004. Adoption and Seed Production Mechanisms of Modern Varieties of Mungbean in Bangladesh. Improving Income and Nutrition by Incorporating Mungbean in Cereal Fallows in the Indo-Gangetic Plains of South Asia DFID Mungbean Project for 2002-2004. Proceedings of the Final Workshop and Planning Meeting. Punjab Agricultural University, Ludhiana Punjab, India.

Almekinders, C. and Richards, P. 2007. Upscaling of participatory approach: An overview of some recent research findings. Paper prepared for 6th Advisory Committee on Science and Technology for ACP Agricultural and Rural Development, hosted by CTA, Wageningen 12-16 November. Technology \& Agrarian Development Group Wageningen University \& Research Centre, The Netherlands.

Chowdhury, M.S.A. 1997. Adoption of BINA Technologies by the Farmers of Boira Union in Mymensingh District. MS (Ag. Ext. Ed.) Thesis, Department of Agricultural Extension Education. Bangladesh Agricultural University, Mymensingh.

Grover, D. K., Weinberger K. and Shanmugasundaram S. 2004. SocioEconomic Impact of New Short Duration 
Mungbean Varieties in Punjab. Improving Income and Nutrition by Incorporating Mungbean in Cereal Fallows in the IndoGangetic Plains of South Asia DFID Mungbean Project for 2002-2004. Proceedings of the Final Workshop and Planning Meeting. Punjab Agricultural University, Ludhiana Punjab, India.

Islam, M. S. 2002. Adoption of Modern Agricultural Technologies by the Farmers of Sandwip. MS (Ag. Ext. Ed.) Thesis. Department of Agricultural Extension Education, Bangladesh Agricultural University, Mymensingh.

Kabir, K. H., Rahman, M. A. and Ahmed, M. S. 2007. Management of Insect Pests of pulses. Pulses for Nutritional Security and Sustainable Agriculture. National Workshop on Pulses. Bangladesh Agricultural Research Institute (BARI) and Australian Center for International Agricultural Research held on 24-25 July 2007 at BARI, Gazipur.

Okoro, F. U. and Obibuaka, L. U. 1992. Factors influencing the adoption of improved oil palm management practices among Small holders in IMO States, Nigeria. Bangladesh Journal of Extension Education, 7: 45-52.

Rahman, N. M. F., Aziz, M. A., Rahman, M. M., and Mohammad, N. 2013. Modeling on grass pea and mungbean pulse production in Bangladesh using ARIMA model. IOSR Journal of Agriculture and Veterinary Science, 6: 20-31.

Robertson, M. J., Carberry, P. S., Lucy, M., Cawthray, S. and Brodie, N. 1989. Participatory research using on-farm monitoring and simulation: spring-sown mungbeans. CSIRO, Tropical Agriculture, Agricultural Production Systems Research Unit, St. Lucia.

Sankhayan P. L. and Sood, K. 1984. "An analytical study of area, yield and production of important pulses in Punjab during 1960-61 to 1980-81", Economic Affairs, 29: 127-132.

Sarkar, D. C. 1997. Correlation of Selected Characteristics of Potato Growers with Their Adoption of Improved Potato Cultivation Practices in Five Villages of Commilla District. MS (Ag. Ext. Ed.) Thesis. Department of Agricultural Extension Education, Bangladesh Agricultural University, Mymensingh.

Shanker, K. M. 1996. Relationship of the Selected Characteristics of Vegetables Growers with Their Level of Knowledge in Vegetable Production Technology. MS Thesis. Department of Agricultural Extension Education, IPSA, Salna, Gazipur. 